\section{Commentary: To art, perchance to science}

\author{
Craig R. Smith, MD
}

To art, perchance to science-aye, there's the rub. This meticulous description of the first author's approach to mitral valve repair ${ }^{1}$ makes a strong argument for "science," by which is meant measurement of leaflet and annular dimensions using calipers and application of an algorithm. The authors argue that application of their algorithm will make mitral repair simpler, more understandable, and more easily adopted by inexperienced surgeons. Several reviewers argued that the only "science" in this algorithm is the unknowable cortical processing of Dr McCarthy's vast experience, and that caliper measurements will be excessively variable because of operator dependence and tissue stretch. Is the algorithm art masquerading as science?

Speaking personally, I always enjoy looking inside the machine to watch the parts move. Whether it's a watch or a car, innumerable engineering details come together in an amazing number of variations to do one thing - to power a driveshaft in axial rotation. Regardless of the level of experience with mitral valve repair, any surgeon will enjoy studying Dr McCarthy's approach and watching the excellent video. To make a mitral valve competent, leaflet coaptation is analogous to the rotating driveshaft, and there are many tricks for creating adequate coaptation. If nothing else, take a moment to stand back and admire the ingenious original "design" (hazardous term in this election year) that makes the mitral valve competent against systolic pressure. I have no doubt that most readers will take away helpful insights that contribute to their success in practice, even if they leave the calipers on the shelf.

\footnotetext{
From the Department of Surgery, Vagelos College of Physicians \& Surgeons of Columbia University, Columbia University Irving Medical Center of New York Presbyterian Hospital, New York, NY.

Disclosures: The author reported no conflicts of interest.

The Journal policy requires editors and reviewers to disclose conflicts of interest and to decline handling or reviewing manuscripts for which they may have a conflict of interest. The editors and reviewers of this article have no conflicts of interest.

Received for publication Oct 19, 2020; revisions received Oct 19, 2020; accepted for publication Oct 21, 2020.

Address for reprints: Craig R. Smith, MD, Columbia University Irving Medical Center of New York Presbyterian Hospital, Milstein Building 7-435, 177 Fort Washington Ave, New York, NY 10032 (E-mail: crs2@cumc.columbia.edu).

J Thorac Cardiovasc Surg 2022;164:877

$0022-5223 / \$ 36.00$

Copyright (c) 2020 by The American Association for Thoracic Surgery

https://doi.org/10.1016/j.jtcvs.2020.10.093
}

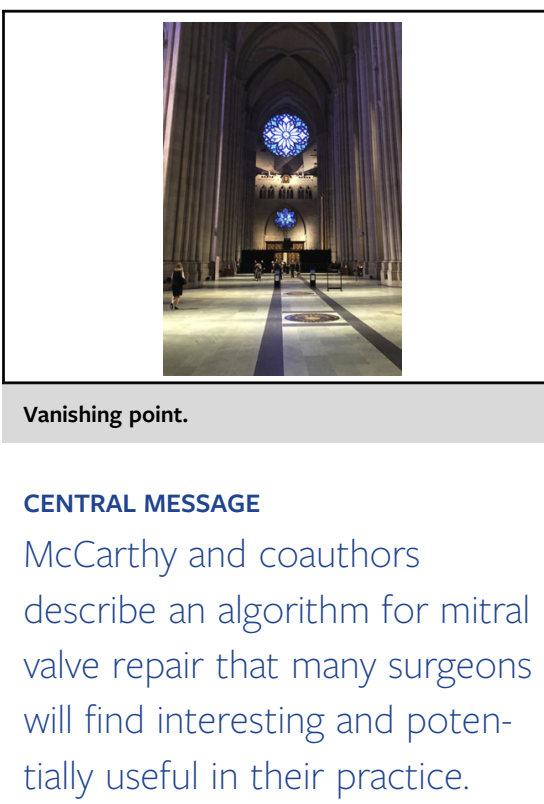

It is heartening to see that Dr McCarthy's patients survive the unspeakable horrors of median sternotomy, as do mine, and that he achieves exemplary results without relying on artificial chords; I like to think I do that also. While we have those things in common, I don't use calipers. I wave an incomplete ring sizer around the annulus to eyeball the biggest ring I think I can get away with, usually $34 \mathrm{~mm}$ or larger. Proof of adequate apposition for me is subjective and rests on aggressive saline pressure-testing, confirmed by transesophageal echo. That personal summary doesn't make my approach or Dr McCarthy's inherently more admirable than any other combination of maneuvers that assures adequate coaptation.

It took visual artists hundreds of years to develop techniques for representing accurate 3 -dimensional perspective in a 2-dimensional plane. Eventually the vanishing point and its orthogonal lines were described in complex mathematics that carry forward into optics and photography, but subjective ability to represent accurate perspective grew in parallel, using tricks like floor tiles and rafters to lead the hand of the artist, then the eye of viewer. It took longer to figure out how to place subjects accurately on the tile floor. The process was neither art nor science, but an evolving, bewitching brew of both, like mitral valve repair. Ay, there's the rub.

\section{Reference}

1. McCarthy PM, Herborn J, Kruse J, Liu M, Andrei A-C, Thomas JD. A multiparameter algorithm to guide repair of degenerative mitral regurgitation. $J$ Thorac Cardiovasc Surg. 2022;164:867-76.e5. 